\title{
An Examination of Conceptualization of Sport Metaphors
}

\author{
Fatih Dervent \\ Correspondence: Fatih Dervent,Marmara University School of Physical Education and Sports, Turkey \\ Received: February 23, 2016 Accepted: March 9, 2016 Online Published: March 14, 2016 \\ doi:10.11114/jets.v4i4.1400 URL: http://dx.doi.org/10.11114/jets.v4i4.1400
}

\begin{abstract}
This study examined the metaphors that were used by athletes, coaches, faculty members, and sport managers to describe the concept of "sport". Participants $(\mathrm{N}=473)$ were asked to reveal the single metaphor they had in minds in the sense of the concept of sport by the prompt "Sport is like ... because ..." 22 valid metaphors were analyzed by content analysis and 5 conceptual categories were identified. Differences in the conceptualization of sport were detected in terms of participants' gender, continents, and professions. Metaphors seem to be an effective tool to have a better understanding of the concept of sport.
\end{abstract}

Keywords: metaphor, conceptualization, sport

\section{Introduction}

Throughout history of humanity, sports have taken a significant part in societies. Individuals have valued sports in different ways. In Ancient Greek, sports had a ritual nature and were played to be worthy of gods' blessing. The prize ceremonies of the games took place in the Temple of Zeus (International Olympic Committee, 2012). Sport has always had the power to unify people. In the era of Roman Empire, sports turned into a free public entertainment, which involved a brutal violence (Auguet, 1994). Sport events were held to have the people of the empire delighted and to prevent uprisings. Sport events were a means of representing the power and the authority of the emperor. For a period of time, Puritan idea abolished sports just because they hindered our responsibilities to the god, while sometimes sports had been flourished to keep men fit for war. In every aspect, sport has been important and central to the culture.

The statistics on the number of people who are spectators and participants are impressive. Events such as cricket world cup, grand slams, and Olympic Games attract millions of people. According to the FIFA (2014) almost one billion people watched 2014 FIFA World Cup final on television. Sport events generate an enormous economy. Athletes are not only athletes anymore. Besides exercising and practicing to perform better, they advertise products of big companies. People spent a vast amount of money on sport. For instance, a 30-seconds commercial sells a record cost of \$5 million in 2016 Super Bowl ${ }^{1}$.

In some cases, people turn sport into a matter of life and death. Athletes are treated as heroes after a win, or they can be treated as traitor after a loss. Sport might have a religious significance. Rituals, costumes, and ceremonies might represent things that we can find their reflections in religions. Siedentop and Van der Mars (2012) emphasize the religious nature of sport. They argue that when done in an appropriate way, sport can teach values that also have religious elements such as perseverance, courage, and sacrifice. Siedentop and Van der Mars (2012) remark that "In sport, there are heroes and heroines who provide perfection to strive for, who are admired for what they did, and who become almost saint-like." (p. 217) Sport is a complicated and serious concept either to comprehend or to explain. As Novak (1993) indicated:

"Sports are not merely fun and games, not merely diversions, not merely entertainment. A ballpark is not a temple, but it isn't a fun house either... No one can explain the passion, commitment, discipline, and dedication involved in sports." (p.23)

Sport brings a full range of diversified images in our minds. Keeping the complexity of sport in mind, I tried to examine how the metaphors of sport that were used by athletes, coaches, sport managers, and faculty were similar and different.

\section{Metaphors}

Metaphor means transport in Greek language. It is a linguistic process of transporting a concept from one conceptual

\footnotetext{
${ }^{1}$ Retrieved from http://www.cnn.com/2013/09/03/us/super-bowl-fast-facts/ on February 7, 2016.
} 
domain to another. A metaphor represents more than its original meaning. It creates new meanings that have not existed before (Thornborrow \& Wareing, 1998). By a metaphor, we try to enlighten the concepts we are not able to comprehend (Mojtabai, 2000; Randall, Jennifer \& Jennifer 2005). It enables us to create correspondences between different concepts in order to understand what we have been experiencing. In other words, we use metaphors to describe our world.

Thanks to metaphors, connections between our minds and the concepts are established as the underlying meanings of the concepts remain unchanged (Kövecses, 2002). According to Lakoff and Johnson (1980), conceptual metaphors structure our thinking. They enable transferring meaning from one object to another on the basis of a perceived similarity (Taggart \& Wilson 1998). Metaphor connects imagination and reality. Hence, we can express our thoughts and behaviors (Cornelissen, Oswick, Christensen \& Phillips 2008; Lopez, 2007). Metaphor functions as a mental model in the sense of comprehending concepts in light of other objects (Kendall \& Kendall, 1993; Morgan, 2006; Short, 2000). They are originated from social and cultural values and what we think is built by metaphors (Martinez, Sauleda \& Huber 2001). This reciprocal relatedness might be explained by Lakoff and Johnson's (1980) definition: “The most fundamental values in a culture will be coherent with the metaphorical structure of the most fundamental concepts in the culture." (p.22). Usage of sport metaphors in language might be related to culture. For instance, as the world's number one sports market, sports related metaphorical expressions are extensively used in the United States (Liu, 2002). In one of his speeches, the US President Barack Obama used gone to the mat $^{2}$ as a wrestling metaphor in order to define the brave attempt to overcome the troubles:

“Tonight, I'm announcing a new national effort to get it done. And because he's gone to the mat for all of us, on so many issues over the past forty years, I'm putting Joe in charge of Mission Control. For the loved ones we've all lost, for the family we can still save; let's make America the country that cures cancer once and for all."

Americans inherently connect sports with their daily lives, which might be interpreted Americans' competitive attitudes towards the world and life (e.g., in social relations, political views, and business).

\section{Sports Metaphors}

People might value sport in different ways based on their backgrounds, cultures, and statuses. According to this, there have been studies related to metaphors that focused different aspects of sport. Mascher (2002) specifies that sports offer important potential for therapy. She remarks that when sport is facilitated metaphorically, it can be an effective therapeutic tool. By using sport as metaphor, a therapeutic relationship creates the bridging, not only a mind-body duality, but also interpersonally. Clark (2009) used football metaphors functioning as a therapeutic activity in order to promote mental health. Football was used as a metaphor for living to cure a football supporter David (pseudonym) who had a mental illness. David was passionate about football. This passion worked as a hope to recover from the mental problem. Football contributed him in terms of personal evaluation and therapeutic growth. Spander, Roy, and Mckeown (2014) also used football metaphor in a group therapy for men who had different psycho-social issues. Results from these studies indicated that football metaphor offered a potential therapeutic support.

Triggs, Lafferty, Brown and Tolley (2011) examine the extent of metaphors whether they support players to cope with career long problems. They used metaphors in song lyrics to encourage youth football players in the sense of expressing their thoughts and feelings. Players developed their communication skills. Besides, they had a better understanding of transition phases of their careers by using metaphors. Metaphors that are being used by athletes to describe performance were studied by Hanin and Stambulova (2002). They put forth that athletes used different metaphors before and after their performances.

Gibson and Zellmer-Bruhn (2001) used the metaphor -work team as sports team- with a focus on a relation between a sport team and a work team. They investigated the fair roles, hierarchy, and specific objectives by sport metaphors. In another study, football was used as a metaphor to interpret teamwork. Some particulars of a football team were used to create a better understanding of organizational teamwork (Bokeno, 2009).

A substantial literature exists on connectedness between warfare metaphors and sports. Warfare metaphors are related with agon, competition, and contest. James (1977) remarked that sports function as "moral equivalents of war." Kellett (2002) investigated warfare terms in football. College students were requested to describe their interactions with football coaches and players by using a metaphor. Students linked coaches to militaristic generals and players to soldiers.

\footnotetext{
${ }^{2}$ Retrieved from

http://www.usatoday.com/story/news/politics/2016/01/12/vice-president-biden-head-pursuit-cancer-cure/78705646/\# on January 12, 2016.
} 
Gassner (1999) asserts that metaphors create an anticipatory mindset that can be used to motivate learners. While he was teaching new athletic skills, he used metaphors to increase students' performance in different sports such as gymnastics, racquetball, and athletics. Different metaphors were used in different sports. For instance, he associated shot put with exploding a bomb. In these studies, metaphors were used as the bridging strategy. A simpler expression for this may be is that in these studies the meaning of an object is transferred to another object (e.g., roles in a football team to military positions).

\section{Method}

In order to examine how sport was conceptualized by athletes, coaches, sport managers, and faculty members, I tried to answer below questions by asking a single metaphor that first came to their minds when they think of sport. (1) What are the metaphorical conceptualizations of sport? (2) Do conceptualizations for sport change according to profession, region, age, and gender? (3) What are the differences and similarities of metaphors among these groups?

\subsection{Participants}

According to the regulations of the university's Institutional Review Board, all the participants gave their informed consent to participate in the study. Sample of this study was constituted of 473 individuals from three continents such as Asia (i.e., India, China, Japan, and Turkey), Europe (i.e., Germany, France, Netherlands, and United Kingdom), and North America (i.e., The United States and Canada).

Table 1. Information about the participants

\begin{tabular}{lllllll}
\hline & & Athlete $f(\%)$ & Coach $f(\%)$ & $\begin{array}{l}\text { Faculty } \\
f(\%)\end{array}$ & $\begin{array}{l}\text { Sport Manager } \\
f(\%)\end{array}$ & Total $f(\%)$ \\
\hline Gender & Female & $53(37.32)$ & $39(30.47)$ & $40(33.33)$ & $47(56.63)$ & $179(37.84)$ \\
& Male & $89(62.68)$ & $89(69.53)$ & $80(66.67)$ & $36(43.37)$ & $294(62.16)$ \\
Education & Graduate & $29(20.42)$ & $50(39.06)$ & $120(100)$ & $83(100)$ & $282(59.62)$ \\
& Undergrad & $113(79.58)$ & $78(60.94)$ & $0(0)$ & $0(0)$ & $191(40.38)$ \\
& $18-22$ & $104(73.24)$ & $21(16.41)$ & $0(0)$ & $19(22.89)$ & $144(30.44)$ \\
& $23-30$ & $34(23.94)$ & $39(30.47)$ & $40(33.33)$ & $8(9.64)$ & $121(25.58)$ \\
& $31-40$ & $4(2.82)$ & $47(36.72)$ & $38(31.67)$ & $45(54.22)$ & $134(28.33)$ \\
Continents & Above 40 & $0(0)$ & $21(16.41)$ & $42(35.00)$ & $11(13.25)$ & $74(15.64)$ \\
& Asia & $113(79.58)$ & $110(85.94)$ & $43(35.83)$ & $30(36.14)$ & $296(62.58)$ \\
& Europe & $14(9.86)$ & $12(9.38)$ & $59(49.17)$ & $26(31.33)$ & $111(23.47)$ \\
& N.America & $15(10.56)$ & $6(4.69)$ & $18(15.00)$ & $27(32.53)$ & $66(13.95)$ \\
\hline
\end{tabular}

Participants declared that they had proficient writing and speaking skills of English language. At the time of the study, participants were actively engaged with sports. Athletes were competitively participating in individual or team sports events (i.e., leagues, tournaments, or championships) from elite to regional level. Coaches were coaching a team or an athlete from elite to regional level. Faculty members were lecturing sports related courses at universities. And, sport managers were working professionally either as an employee in a private company or running their own businesses.

\subsection{Data Collection}

Participants were prompted with the sentence "Sport is like $\mathrm{a} / \mathrm{n}$ because ." First, they were asked to fill in the blanks with the first metaphor (i.e., first blank) that came to their minds when they read the sentence. Then, they were requested to give an explanation (i.e., second blank) related to the metaphor they used. I used the terms such as "like" and "because" in order to probe the rational and the logic of the metaphors that were used by participants (Saban, 2010). Hereby, written expressions of participants formed the data corpus of the study. Data were collected during four international sport related (i.e., sport, physical education, health, and Olympics) scientific or cultural events. After having information such as age, education, profession, and continent, data collected in almost 5 minutes from each participant.

\subsection{Data Analysis}

Content analysis was used to analyze the metaphors and the explanations of the participants. Content analysis allows categories to emerge from the data itself (Marshall \& Rosmann 1999). Before starting to code, each metaphor and its explanation were read in order to ensure an overall view of the data. In the initial phase of the data analysis, each metaphor and rationale between the metaphors and its explanation scrutinized. Some sentences that were filled out by participants unclassified, if (1) either one or two of the blanks in the sentence were left blank, (2) contained an opinion or a definition instead of a metaphoric expression (e.g., An activity involves physical activity), or (3) the explanation did not include a rational and the logical basis of the metaphor (e.g. Because, sport gives me an employment). In total, 79 papers were excluded from the main data of the study due the above mentioned reasons.

After the exclusion of weak structured data, 22 valid metaphors were emerged. Metaphors were employed as codes to make sense of the data. An alphabetical list of codes was utilized. First, each valid code was examined in the sense of its 
relevance to common characteristics of sport. A tentative grouping of codes was made to lead the formation of conceptual categories. Then, each valid code was constantly examined in the sense of logical cohesion between the code and the conceptual categories. In the end, 22 codes were sorted out into 5 conceptual categories and the list of conceptual categories including codes was formed (Table 2). Some of the codes were regarded as dominant by dividing the number of participants to number of codes (i.e., 473/22). According to this calculation, the mean participant number per a metaphor was 22.5. Hence, 13 metaphors were determined as dominant codes (e.g., used by at least 22 participants). The dominant codes were displayed in bold letters.

Table 2. Classification of metaphors by conceptual categories

\begin{tabular}{|c|c|}
\hline Conceptual categories $f(\%)$ & Codes $f(\%)$ \\
\hline Life $146(30.87)$ & to live $99(67.81)$, lifestyle $40(27.40)$, re-birth $7(4.79)$ \\
\hline Emotion $121(25.58)$ & $\begin{array}{l}\text { joy } 36(29.75) \text {, beauty } 25(20.66) \text {, happiness } 24(19.83) \text {, pleasure } 11 \text { (9.09), } \\
\text { freedom } 10(8.26) \text {, passion } 10(8.26) \text {, relaxation } 5(4.13),\end{array}$ \\
\hline Essential $92(19.45)$ & $\begin{array}{l}\text { water } 26(28.26) \text {, health } 23(25) \text {, breathe } 22(23.91) \text {, food } 11 \text { (11.96), medicine } 4 \\
(4.35) \text {, nutrition } 3(3.26) \text {, sun } 3(3.26)\end{array}$ \\
\hline Interaction 69 (14.59) & festival $25(36.23), \quad$ stage $22(31.88)$, unity $22(31.88)$ \\
\hline Dependency $45(9.51)$ & addiction $23(51.11)$, religion $22(48.89)$ \\
\hline
\end{tabular}

In order to test the reliability of the study, the list of 22 codes and the list of 5 conceptual categories were separately provided to an expert. At the time of the study, the expert was working as a faculty member at a university in Midwest USA. And, he has been teaching sport related courses for over 20 years. The expert was requested to group the 22 codes into the 5 conceptual categories. Then, the list created by the expert was compared to my list. The expert classified 2 codes into different conceptual categories. The percentage of inter-coder agreement was calculated using the following formula. Number of agreed codes divided by total number of codes (i.e., agreement plus disagreement) and then multiplied by 100 . As a result, the reliability was found $91 \%$, which was above the $85 \%$ the acceptable criterion for inter-coder reliability (Cooper, Heron \& Heward, 2007).

\section{Findings}

This section mentions the general findings derived from the study. The 5 conceptual categories developed as a part of this study in respect of the concept of sport and the attributes of each category were described with references to the sample metaphors expressed by the participants. The 5 conceptual categories were compared and contrasted by the demographic characteristics of the participants. The overall findings obtained reveal that the participants created 22 valid metaphors in the sense of the concept of sport.

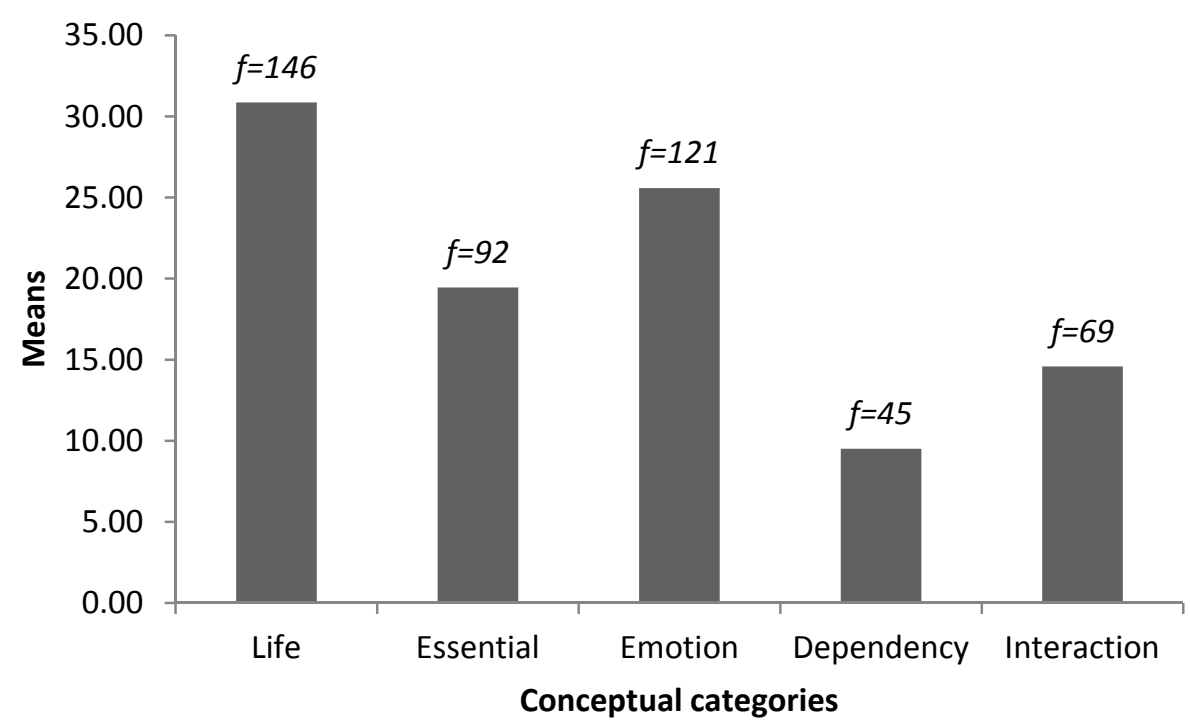

Figure 1. Means and frequencies of conceptual categories

Table 1 presents the overall means and frequencies of the conceptual categories. Participants mostly referred sport to "Life" (30.87\%), while the second most cited conceptual category was "Emotion" (25.58\%). The personal information of the participants was provided within brackets, immediately following the expressions of participants. The meanings implied by the codes assigned are as follows: (1) the gender of the concerned participant was stated by either the letter 
$\mathrm{M}$, representing male, or the letter F, representing female; (2) the profession of the participant, who stated the metaphoric expression, was set forth as an athlete, a coach, a faculty, and a sport manager as appropriate; (3) the continent where the participant was from specified by A, representing Asia, E, representing Europe, and N, representing North America. Ages and educational levels of the participants were not stated as there was no meaningful difference between these groups in terms of the use of metaphors.

5.1 Sport as Life

146 participants $(30.87 \%)$ referred to "sport as life" as it was the most cited category. To live $(f=99)$ and lifestyle $(f=40)$ were the most used metaphors, respectively. The sample metaphors featured by this category are provided as follows:

Sport is like to live because...

"My work is sport, my life is sport, and it means to me I cannot live without sport." (M/Coach/NA)

"Can you live without sport? Yes you can, but those who do sport they live longer because they feel mentally, physically better. ... it [sport] is your source to live [better]." (M/Coach/E)

"It is all being alive, without it [sport] you do not really live." (F/Faculty/NA)

Sport is like lifestyle because...

"Sport influences the way I see life and the way I live it." (M/Coach/A)

"I am in debt to sport for what I have learned. Sport has shaped my life." (M/Athlete/NA)

"It [sport] has given me focus and direction, discipline, and tolerance... all the things to find my way in life." (M/Coach/NA)

"Sport shines upon on my way of life." (F/Athlete/A)

\subsection{Sport as an Emotion}

The conceptual category "sport as an emotion" was cited by 121 participants $(25.58 \%)$. Participants used the metaphors joy $(f=36)$, beauty $(f=25)$, happiness $(f=24)$, pleasure $(f=11)$, freedom $(f=10)$, passion $(f=10)$, and relaxation $(f=5)$ to link emotions to sport.

Sport is like joy because...

"I enjoy doing sport, but most of all I enjoy the atmosphere hanging around sport. It does not matter if I am practicing or watching it [sport]." (F/Athlete/E)

"For me the idea behind sport is to have joy, to play, to keep in good health, while doing something pleasant." (F/Faculty/E)

"I enjoy the way it helps me to loose thoughts and live in the moment." (M/Sport Manager/NA)

"I know I haven't wasted a single second while enjoying sport." (F/Athlete/NA)

Sport is like beauty because...

"I am infatuated with sport... the performance of an athlete is the expression of her beauty [to me]." (F/Athlete/E)

"Only with sport, your beauty exists forever." (F/Athlete/E)

Sport is like happiness because...

"Sport is pursuit of happiness ... all this hard work is not just for medals but for being happy." (M/Athlete/A)

"All I want to be happy and it [sport] just makes me happy." (F/Athlete/E)

"Active life [means] happy life." (F/Faculty/E)

\subsection{Sport as an Essential Element}

$92(19.45 \%)$ participants related sport to an essential element. Metaphors that used to describe sport were water $(f=26)$, health $(f=23)$, breathe $(f=22)$, food $(f=11)$, medicine $(f=4)$, nutrition $(f=3)$, and sun $(f=3)$. Explanations from some participants are provided below.

Sport is like water because...

"Water is essential for life, so is sport. It [sport] makes me alive." (F/Athlete/E)

"Without it [sport] I dry out." (M/Faculty/A)

Sport is like health because...

"Sport is an inexpensive way to prevent many diseases." (F/Faculty/A) 
"It [sport] helps me to keep my body and mind fit." (M/Athlete/A)

Sport is like breathe because...

"You feel better while and after doing sports. It feels as if I can breathe more deeply, I feel more awake and alive." (M/Athlete/E)

"Like I need to breathe, I need sport." (M/Coach/E)

5.4 Sport as Interaction

The conceptual category "interaction" was cited by 69 participants $(14.59 \%)$. Festival $(f=25)$, stage $(f=22)$, and unity $(f=22)$ were the codes that referred to sport.

Sport is like a festival because

"Sport is about doing things and striving together towards mutual goals." (M/Athlete/NA)

"It [sport] is a great way to come together with friends even people that you don't know." (M/Coach/A)

"It gives you the opportunity to make new friends and learn about different people and cultures." (M/Faculty/E)

Sport is like a stage because

"It [sport] involves a challenge to accomplish a goal and perform it." (M/Athlete/NA)

"It [sport] gives space for competitive spirit to be developed and aggression to be released in a safe environment and without causing harm." (F/Faculty/E)

Sport is like unity

"Like Mandela said "sport has the power to change the world". It can unite the people no matter of ethnos, religion, sex or color of skin they might have." (M/Faculty/NA)

"Sport connects us all." (M/Coach/A)

5.5 Sport as Dependency

"Sport as dependency" was the least cited conceptual category. Only 45 participants $(9.51 \%)$ connected metaphors to sport within this category. "Addiction" $(f=23)$ and "religion" $(f=22)$ were the featured metaphors in this category.

Sport is like addiction because

"I need sport like a baby needs her mom." (M/Athlete/NA)

"I have always done it [sport] and I will always be depended to it." (F/Athlete/A)

Sport is like religion

"Both [sport and religion] might be opium for people." (F/Faculty/E)

"It [sport] makes me feel peaceful. I feel the same when I pray." (F/Coach/A)

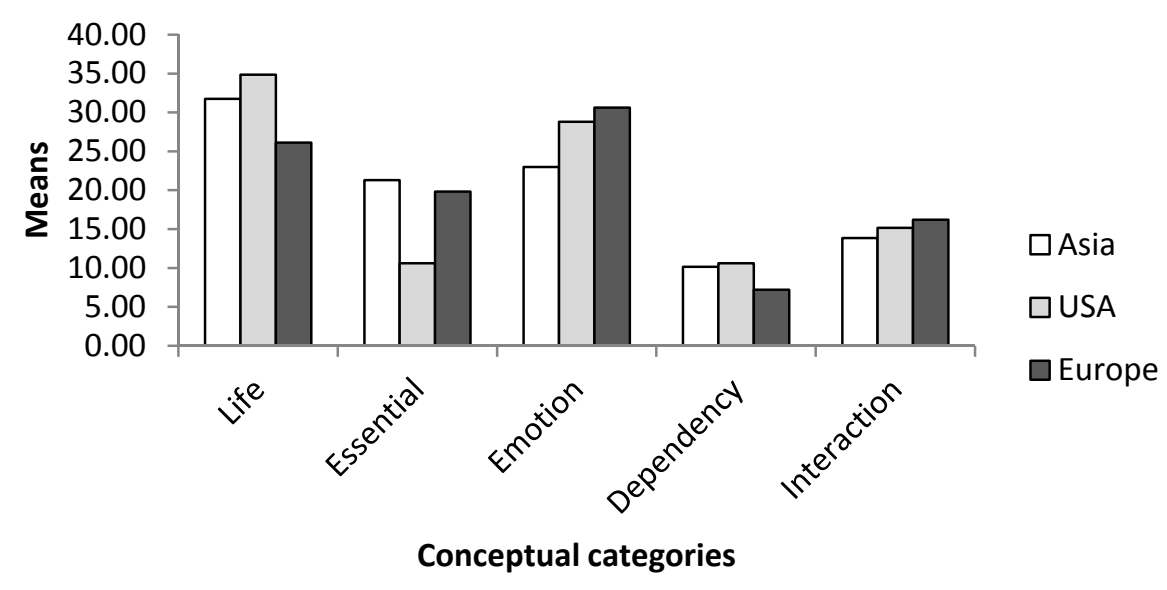

Figure 2. Means of conceptual categories according to participants' continents

Sports and geographical locations both are the ingredients of culture. The differences based on geographical locations on sports can be seen in Figure 2. The means of conceptual metaphors according to participants' continent were 
displayed. Some differences were detected in the conceptual categories of "sport as life" and "sport as an essential element."

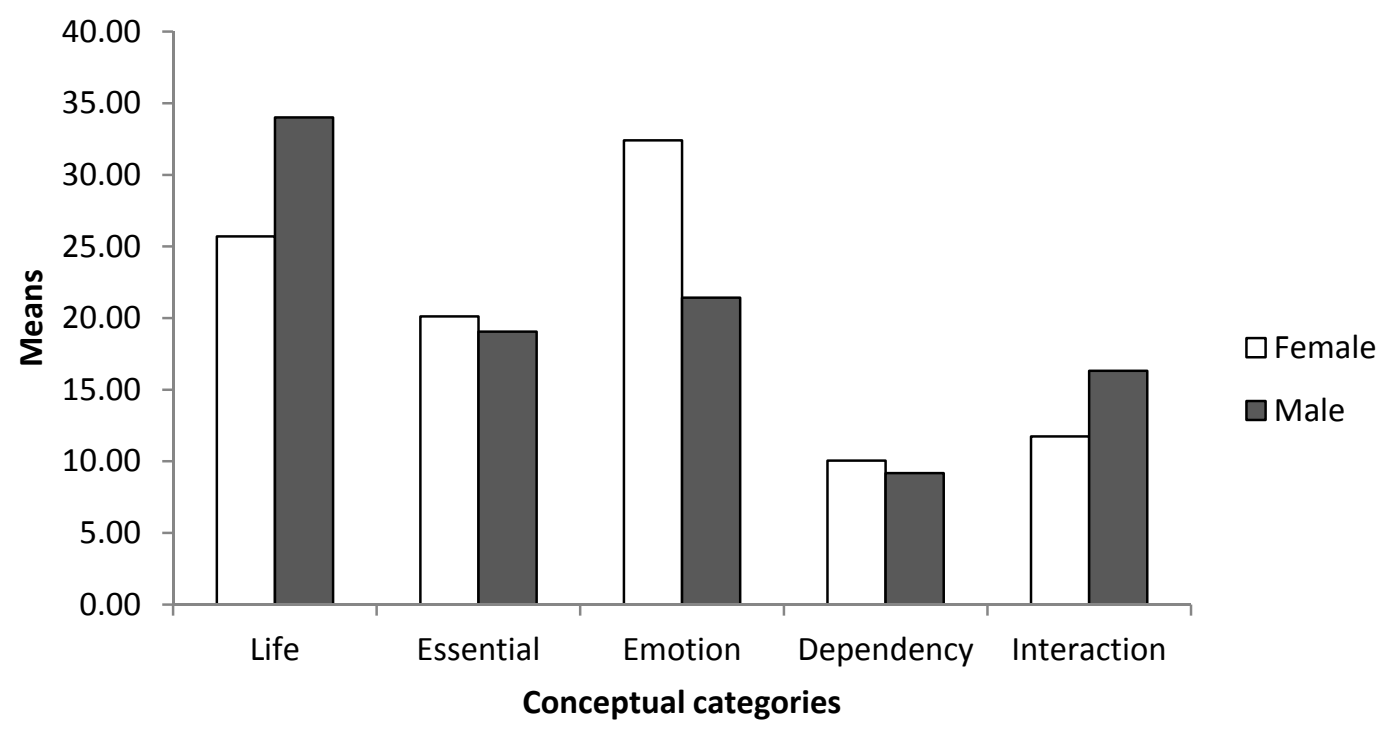

Figure 3. Means of conceptual categories according to genders

Even though the gap between women and men in sports seems to be closed, there are still differences in terms of conceptualization of sport such as masculinity, femininity, and aesthetic. Figure 3 shows the differences between the conceptual categories in terms of the gender of the participants. Female participants used more metaphors within "sport as an emotion" conceptual category comparison to male participants. On the contrary, metaphors of "sport as life" conceptual category were mostly used by male participants.

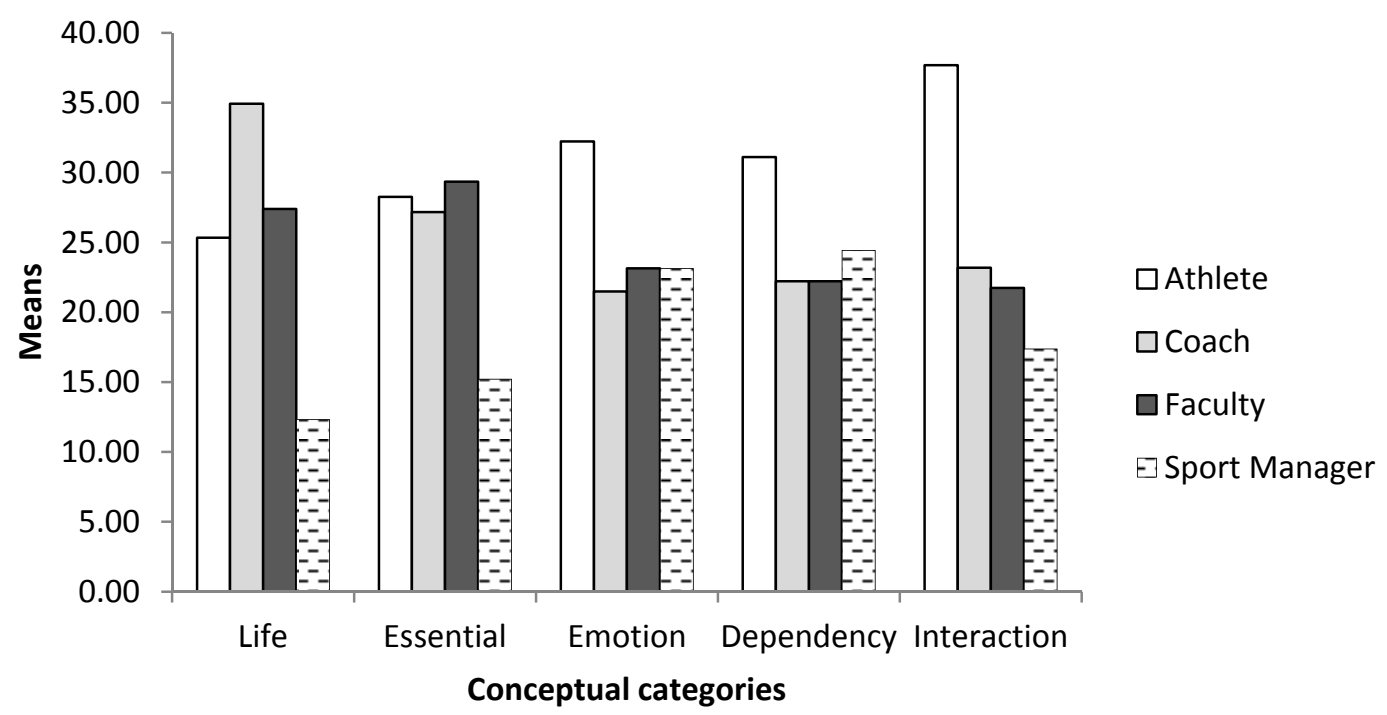

Figure 4. Means of conceptual categories according to profession

Figure 4 represents the mean of conceptual categories based on the professions of the participants. Athletes used more metaphors related to "sport as interaction" conceptual category than others. Besides, coaches seemed to link sports to metaphors of the "sport as life" conceptual category.

\section{Discussion}

The participants of this study were among the main characters of sport such as athletes, coaches, faculty members, and sport managers. I tried to examine their conceptualizations of sport by asking a single metaphor that first came to their 
minds when they think of sport. Results obtained from the study showed the differences between the participants in terms of continents, genders, and professions.

The literature indicates that sport is an important element of culture so are the geographical locations. Sports might originate from the properties of the place. Geographical features might determine the type of popular sports in a particular area. The sports played in any area (i.e., region, country, and continent) influence the meanings that are associated with that area (Rooney \& Pillsbury, 1992). In addition, these features might affect how people value sports. Some differences were detected in the conceptual categories of "sport as life" and "sport as an essential element" according to continents of the participants. Standeven and De Knop associated the experience of physical activity with the experience of place. They viewed the sport as "a cultural experience of physical activity" (1999, p. 58). Higham and Hinch (2006) assert that sport plays a central role as a manifestation of culture. The differences between the participants according to their continents might be interpreted by these cultural influences on sports that are specific to the places.

In many countries, sport has still been regarded as a male domain. It might sound odd but 2012 London Olympics were the first Games that all participating countries had women athletes in their teams. In this study, female participants referred to metaphors within the conceptual category of "sport as an emotion" more than males. It was significant that the metaphor "beauty" was used by only female participants (i.e., one exception). This finding seems to be in line with study of Klomsten, Marsh, and Skaalvik (2005) in which the gender differences of masculine and feminine characteristics of sports were examined. The results indicated that both boys and girls regarded boys stronger, more aggressive, and able to bear more pain than girls. Girls were considered more graceful, coordinated, and flexible as well as caring. Boys also valued sport in the sense of strength and endurance, while girls regarded sport as appearance. Colley, Berman, and Van Millingen (2005) conducted a study to investigate the adolescent girls' and boys' perceptions of sport. They used a test named Draw a Sportsperson. Participants were asked to draw either real or imaginary person who does a lot of sport. They were also asked to give a name for the person they drew. Gender differences were found in all aspects of the drawings. Almost all of the boys in both age groups drew male figures, whereas the girls drew figures of both sexes.

Studies revealed that having abilities and doing well in sports is much more important for the boys than the girls (Eccles, Wigfield, Harold, \& Blumenfeld, 1993; Jacobs, Lanza, Osgood, Eccles, \& Wigfield, 2002). In this study, metaphors in the "sport as life" conceptual category were mostly used by male participants. One of the athlete participants underlined how his trainings became an important part of his life. He emphasized that he needed to train harder to become better and said "Whatever I do is based on it [sport]. The time that I wake up, the time that I go to bed, what I eat, what I drink." This seems to be consistent with above mentioned studies, which indicated gender stereotyping. These findings might be concluded as the substantial cultural influences of male stereotype of sport.

As individuals have different motives towards sports, there are different conceptualizations among the professions. In their metaphorical conceptualization of football coach study, Dervent and Inan (2015) revealed the differences of the use of metaphors between different professions such as club officials, referees, and players. In the current study, athletes referred to metaphors within the conceptual category of "sport as interaction" more than other professions. On the other hand, the conceptual category "sport as life" was mostly cited by coaches. This seems to suggest that use of metaphors differs based on the profession as the function of individuals differs depending on their social roles and statuses (Bandura, 1989).

\section{Limitations and Suggestions for Future Studies}

Sample size is one of the limitations of this study. Despite the efforts to reach more participants, only 473 individuals from 3 different continents consented to take part in the study. Thus, only the conceptualizations of the participants were represented. Although, the participants claimed that they were proficient in English, they might have had difficulties in terms of expressing the depth of language in their explanations. The participants were athletes, coaches, faculty members, and sport managers who were actively engaged in sports. Future studies might aim to reach more participants not only from sport related professions but also others (i.e., teachers, supporters, and referees) to have a broader understanding of the conceptualization of sport.

\section{References}

Bandura, A. (1986). Social foundations of thought and action: A social cognitive theory. Englewood Cliffs, NJ: Prentice-Hall, Inc.

Bokeno, M. R. (2009). An alternative sports metaphor for understanding teamwork as complex: Soccer. $E: C O, 11(2)$, 79-86.

Clarke, L. (2009). Football as a metaphor: Learning to cope with life, manage emotional illness and maintain health through to recovery. Journal of psychiatric and mental health nursing, 16,488-492. 
http://dx.doi.org/10.1111/j.1365-2850.2009.01403.x

Colley, A., Berman, E., \& Millingen, L. (2005). Age and gender differences in young people's perceptions of sport participants. Journal of applied social psychology, 35(7), 1440-1454. http://dx.doi.org/10.1111/j.1559-1816.2005.tb02178.x

Cooper, J. O., Heron, T. E., \& Heward, W. L. (2007). Applied Behavior Analysis. Upper Saddle River, NJ: Pearson-Prentice Hall.

Cornelissen, J. P., Oswick, C., Christensen, L. T., \& Phillips, N. (2008). Metaphor in organizational research: Context, modalities and implications for research introduction. Organization Studies, 29(7), 8-22. http://dx.doi.org/10.1177/0170840607086634

Cushion, C. (2007). Modelling the complexity of the coaching process. International Journal of Sports Science and Coaching, 2(4), 395-401. http://dx.doi.org/10.1260/174795407783359650

Cushion, C. J., Armour, K, M., \& Jones, R. L. (2006). Locating the coaching process in practice: Models for and of coaching. Physical Education and Sport Pedagogy, 11(1), 1-17. http://dx.doi.org/10.1080/17408980500466995

Dervent, F., \& Inan, M. (2015). Metaphorical conceptualizations of football coach through social cognitive theory. Journal of Education and Training Studies, 3(4), 158-168. http://dx.doi.org/10.11114/jets.v3i4.826

Eccles, J., Wigfield, A., Harold, R. D., \& Blumenfeld, P. (1993). Age and gender differences in children's self - and task perceptions during elementary school. Child development, 64(3), 830-847. http://dx.doi.org/10.2307/1131221

Gibson, C. B., \& Zellmer-Bruhn, M. E. (2001). Metaphors and meaning: An intercultural analysis of the concept of teamwork. Administrative Science Quarterly, 46(2), 274-303. http://dx.doi.org/10.2307/2667088

Gregory, J. G. (1999). Using metaphors for high-performance teaching and coaching. Journal of Physical Education, Recreation and Dance, 70(7), 33-35. http://dx.doi.org/10.1080/07303084.1999.10605684

Hanin, Y. L., \& Stambulova, N. B. (2002). Metaphoric description of performance states: An application of the IZOF model. The Sport Psychologist, 16, 396-415.

Higham, J., \& Hinch, T. (2006). Sport and tourism research: A geographic approach. Journal of Sport \& Tourism, 11(1), 31-49. http://dx.doi.org/10.1080/14775080600985267

Jacobs, J. E., Lanza, S., Osgood, D. W., Eccles, J. S., \& Wigfield, A. (2002). Changes in children's selfcompetence and values: Gender and domain differences across grades one through twelve. Child development, 73(2), 509-527. http://dx.doi.org/10.1111/1467-8624.00421

Kellett, P. (2002). Football-as-war, coach-as-general: Analogy, metaphor and management implications. Football Studies, 5(1), 60-76.

Kendall, J. E., \& Kendall, K. E. (1993). Metaphors and methodologies: Living beyond the systems machine. MIS Quarterly, 17(2), 149-171. http://dx.doi.org/10.2307/249799

Klomsten, A. T., Marsh, H. W., \& Skaalvik, E. M. (2005). Adolescents' perceptions of masculine and feminine values in sport and physical education: A study of gender differences. Sex roles, 52(9-10), 625-636. http://dx.doi.org/10.1007/s11199-005-3730-x

Kövecses, Z. (2002). Metaphor: A practical introduction. New York: Oxford University Press.

Lakoff, G., \& Johnson, M. (1980). Metaphors we live by. Chicago, IL: University of Chicago Press.

Liu, D. (2002). Metaphor, culture, and worldview: The Case of American English and the Chinese Language. New York: University Press of America.

Lopez, J. J. (2007). Notes on metaphors, notes as metaphors: The genome as musical spectacle. Science Communication, 29(7), 1-29. http://dx.doi.org/10.1177/1075547007305165

Martinez, M., Sauleda, N., \& Huber, G. (2001). Metaphors as blueprints of thinking about teaching and learning. Teaching and Teacher Education, 17, 965-977. http://dx.doi.org/10.1016/S0742-051X(01)00043-9

Mascher, J. (2002). Narrative Therapy, Women \& Therapy, 25(2), 57-74. http://dx.doi.org/10.1300/J015v25n02_05

Mojtabai, R. (2000). Delusion as error: The history of a metaphor. History of Psychiatry, 11(3), 1-13. http://dx.doi.org/10.1177/0957154x0001104101

Morgan, G. (2006). Images of organization. London: Sage Publication.

Novak, M. (1976). The joy of sports. New York: Basic Books. 
Randall, E. G., Jennifer, A., \& Jennifer, B. (2005). Pre-service elementary school teachers' metaphors for the concept of statistical sample. Statistics Education Research Journal, 4(2), 27-42.

Rooney, J. F., \& Pillsbury, R. (1992). Sports regions of America. American Demographics, 14(10), 1-10.

Saban, A. (2010). Prospective teachers' metaphorical conceptualizations of learner. Teaching and Teacher Education, 26, 290-305. http://dx.doi.org/10.1016/j.tate.2009.03.017

Schnitzer, M. L., \& Pedreira, M. A. (2005). A neuropsychological theory of metaphor. Language Sciences, 27(1), 31-49. http://dx.doi.org/10.1016/j.langsci.2004.10.001

Shields, D., \& Bredemeier, B. (2011). Contest, competition and metaphor. Journal of Philisophy of Sport, 38, 27-38. http://dx.doi.org/10.1080/00948705.2011.9714547

Short, D. C. (2000). Analysing metaphor in human resource development. Human Resource Development International, 3(3), 323-341. http://dx.doi.org/10.1080/13678860050128500

Siedentop, D., \& Van der Mars, H. (2012). Introduction to physical education, fitness, and sport. New York: McGraw Hill.

Spander, H., Roy, A., \& Mckeown, M. (2014). Using football metaphor to engage men in therapeutic support. Journal of Social Work Practice, 2(28), 229-245. http://dx.doi.org/10.1080/02650533.2013.853286

Standeven, J., \& De Knop, P. (1999). Sport tourism. Champaign, IL: Human Kinetics.

Taggart, G. L., \& Wilson, A. P. (1998). Promoting reflective thinking in teachers: 44 action strategies. California: Corwin Press.

Thornborrow, J., \& Wareing, S. (1998). Patterns in language: An introduction to language and literary style. London: Routledge.

Triggs, C., Lafferty, M. E., Brown, H. E., \& Tolley, H. L. (2011). Metaphorical use of song lyrics within sport psychology practice: Targeting the transition within a premier league football youth academy. Journal of Sport Psychology in Action, 2(3), 183-195. http://dx.doi.org/10.1080/21520704.2011.619046

\section{$(\mathrm{cc}) \mathrm{Br}$}

This work is licensed under a Creative Commons Attribution 3.0 License. 